\title{
Reuso de latinhas de alumínio recicláveis para tratamento de águas residuais da produção de biodiesel via eletrofloculação
}

\section{Samara Pereira Vieira ${ }^{1}$, Fabiano Almeida Nascimento ${ }^{1}$, Mayara de Araújo Braz ${ }^{2}$, Sizenando José de Andrade Júnior ${ }^{4}$, Luiz Antônio Pimentel Cavalcanti ${ }^{5}$}

${ }^{1}$ Instituto Federal de Educação, Ciência e Tecnologia da Bahia, Campus de Paulo Afonso, Rua Marcondes Ferraz, 200, Bairro General Dutra, Paulo Afonso-BA (CEP 48607-000). Graduando em Engenharia Elétrica.

${ }^{2}$ Instituto Federal de Educação, Ciência e Tecnologia da Bahia, Campus de Paulo Afonso, Rua Marcondes Ferraz, 200, Bairro General Dutra, Paulo Afonso-BA (CEP 48607-000). Técnica em Biocombustíveis: E-mail: mayara_braz07@hotmail.com.

${ }^{3}$ Instituto Federal de Educação, Ciência e Tecnologia da Bahia, Campus de Paulo Afonso, Rua Marcondes Ferraz, 200, Bairro General Dutra, Paulo Afonso-BA (CEP 48607-000). Mestre em Genética e Biologia Molecular. E-mail: sizenando.andrade@ifba.edu.br.

${ }^{4}$ Instituto Federal de Educação, Ciência e Tecnologia da Bahia, Campus de Paulo Afonso, Rua Marcondes Ferraz, 200, Bairro General Dutra, Paulo Afonso-BA (CEP 48607-000). Doutor em Engenharia Química e Professor do Ensino Básico, Técnico e Tecnológico (EBTT). E-mail: luiz.cavalcanti@ifba.edu.br.

Resumo. A etapa de purificação de biodiesel gera águas residuais que na sua composição apresentam contaminantes que inviabilizam o seu lançamento em corpos d'água nas condições estabelecidas pela Resolução CONAMA n ${ }^{\circ}$ 430/2011. Com a crise hídrica instalada no mundo, a comunidade científica tem intensificado os estudos sobre técnicas de tratamento e reuso da água. O processo de eletrofloculação foi usado para o tratamento das águas residuais da etapa de purificação do biodiesel. O tratamento foi realizado em reator eletroquímico constituído a partir de latinhas de alumínio recicladas em formato retangular de com $9 \mathrm{~cm}$ de comprimento e $3 \mathrm{~cm}$ de largura. Os eletrodos foram fixados em um béquer de $0,5 \mathrm{~L}$ através de uma estrutura metálica, e a eles foram soldados fios que se ligam à fonte geradora de corrente contínua de intensidade 1,0 A, alimentado por um sistema fotovoltaico. Após o tratamento a amostra foi submetida a um processo de filtração através de papel de filtro. Ao fim do processo a amostra foi filtrada e submetida aos estudos de parâmetros como cor aparente, turbidez, DQO, DBO, óleos e graxas. Que quando comparado com os valores obtidos antes da eletrofloculação foi verificado uma atenuação dos valores de turbidez (97\%), cor aparente (100\%), DQO (85\%), DBO5 (87\%) e óleos e graxas (84\%).

Palavras-chave: Biodiesel, Água residual, Eletrofloculação.

Abstract. Reuse of aluminium recyclable cans to water treatment of biodiesel production by way of eletroflocculation. The biodiesel purification step generates a type of wastewater which presents, in its composition, contaminants that prevent their disposal into water

Recebido: 30/09/2015

Aceito: 18/11/2015

Publicado: 31/12/2015

Acesso Aberto Artigo completo

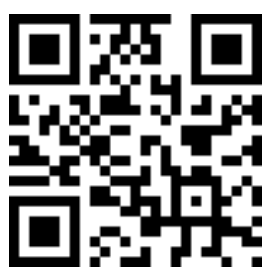


bodies under the conditions set by Resolution $n^{\circ} 430 / 2011$, of the Brazilian National Environment Council (CONAMA). With the installed water crisis in the World, scientific community has intensified studies on treatment techniques and water reuse. The electroflocculation process has been used aiming the treatment of wastewater from biodiesel purification step. The treatment was carried out in the electrochemical reactor constructed from aluminum cans recycled into rectangular shape of $12 \mathrm{~cm}$ long and $4 \mathrm{~cm}$ wide. The electrodes were placed in a $0.5 \mathrm{~L}$ Becker through a metal structure, than welded in wires and connected to the $1.0 \mathrm{~A}$ direct current source, powered by a photovoltaic system. After treatment the sample was subjected to a filtration process through a filter paper. At the end of the process the sample was filtered and subjected to studies parameters as apparent color, turbidity, COD, BOD, oils and greases. When compared with the values obtained before electroflocculation was observed attenuation of turbidity values (97\%), apparent color (100\%), COD (85\%), BDO5 (87\%), and oils and greases (84\%).

Keywords: Biodiesel, Residual water, Electroflocculation.

\section{Introdução}

Com a preocupação crescente sobre a disponibilidade de um recurso como a água, a reutilização de águas residuais tratadas configura uma prática sustentável e viável para os processos industriais. A crise hídrica tem causado impactos negativos na produção de energia elétrica no país que no atual cenário de desenvolvimento industrial associado ao crescimento da população é caracterizado por um aumento crescente do consumo energético (Ebiotecnologia, 2015).

Na produção do biodiesel, geralmente recorre-se à etapa de purificação, com separação da glicerina formada como subproduto, seguida de lavagem com solução ácida, para retirada de resíduos de óleo não reagido do catalisador, e com álcool, e finalmente algumas lavagens com água para a retirada de resquícios de resíduos ainda presentes no biodiesel. Essa água pós-lavagem contém uma quantidade elevada de resíduos, que deve ser tratada antes do reuso ou descarte. O processo de purificação convencional com água, apesar de apresentar significativa eficiência, gera um grande volume de efluente líquido que, devido às impurezas presentes, não pode ser descartado diretamente nos cursos d'água, conforme os parâmetros estabelecido na Resolução CONAMA nº 430/2011 (Fleck, 2011).
O tratamento da água de lavagem na produção de biodiesel pode ser feito pela aplicação de processos físicos, biológicos, químicos ou eletroquímicos, tais como a filtração, a adsorção, a eletrofloculação, a coagulação, a decantação e a floculação (Brito et al., 2012). Dentre esses processos, destaca-se a eletrofloculação, que se utiliza de uma eletrólise para separação entre os resíduos e a água, com posterior filtração. A separação por esse método é simples e eficiente, garantindo as especificações necessárias de redução de resíduos (Schllemer et al., 2008).

De acordo com Singh (2012), o consumo de energia elétrica pode ser dispendioso em algumas regiões do país para aplicação no tratamento de águas residuais via eletrofloculação, tornando o processo inviável economicamente. No entanto se um sistema fotovoltaico for utilizado como fonte de geração de corrente elétrica para o processo, o tratamento pode ser aplicado a diversos tipos de efluentes com os mesmos resultados daqueles obtidos pelo uso da energia elétrica da rede, porém com baixo custo.

Geralmente, na eletrofloculação são utilizados eletrodos de alumínio ou ferro que proporciona um ambiente físicoquímico permitindo a inabilitação do poluente pela oxidação eletrolítica e sua coagulação, adsorção, precipitação e flutuação, sucessivamente (Brito et al., 
2012). A substituição desses eletrodos pelo alumínio oriundo de latinhas reutilizadas gera a diminuição dos resíduos sólidos, como recomenda a Política Nacional de Resíduos Sólidos (PNRS), que tem crescido muito nos últimos anos, devido ao descarte inadequado dos resíduos.

No presente trabalho foi produzido o biodiesel a partir de óleo de soja por meio de transesterificação alcalina na comparência de $\mathrm{KOH} / \mathrm{CH}_{3} \mathrm{OH}$, em que sua água de lavagem excedente foi tratada via eletrofloculação com eletrodos de alumínio construídos a partir da reutilização de latinhas, sendo o sistema alimentado por uma central fotovoltaica. Após o tratamento, a água purificada foi submetida a uma avaliação de variáveis como $\mathrm{pH}$, turbidez, DBO5, DQO, cor aparente, óleos e graxas. A fim de verificar se está de acordo com as normas ambientais regidas pela Resolução CONAMA nº 430/2011 (Brasil, 2011).

\section{Materiais e métodos}

A célula eletrolítica para o processo foi montada em recipiente de vidro, empregando como eletrodos construídos a partir de resíduos de latinhas de alumínio, cortadas e lixadas para retirar a tinta, com dimensões de $9 \mathrm{~cm}$ de comprimento e $3 \mathrm{~cm}$ de largura. Uma fonte alimetadora (B\&K Precision, modelo 1900) foi usada para a geração da corrente contínua no processo, ligada a um sistema fotovoltaico. Os compostos químicos como metanol, hidróxido de sódio e ácido clorídrico com 99\% de pureza foram obtidos junto à VETEC, Sigma-Aldrich Brasil (Nascimento et al., 2015).

\subsection{Produção do biodiesel}

O biodiesel metílico de soja (B100-S) foi produzido através da reação de transesterificação alcalina em presença de $\mathrm{KOH}$, com razão molar óleo:metanol de 1:6. O processamento foi desenvolvido em reator de vidro (Marconi, modelo MA502/5/C, volume útil $1 \mathrm{~L}$ ) com controle de temperatura e agitação mecânica (impelidor do tipo pás), nas condições operacionais: $50^{\circ} \mathrm{C}, \quad 1 \mathrm{~atm}, \quad 300 \mathrm{rpm}$ e tempo reacional de $1 \mathrm{~h}$. Em seguida, procedeu-se a separação da glicerina da mistura reacional via decantação. A fase mais leve da mistura contendo o B100, o catalisador e o excesso de metanol, passou pela etapa de purificação que constou de evaporação do metanol com auxílio de um evaporador rotativo (IKA, modelo RV10) com condensador vertical, seguida de uma lavagem ácida com solução de ácido clorídrico $0,5 \mathrm{M}$. Lavagens posteriores foram realizadas com água destilada. As águas residuais resultantes do processo de purificação foram colhidas em recipientes adequados e submetidas ao tratamento de eletrofloculação (Cavalcanti, 2013).

\subsection{Sistema fotovoltaico e dispositivo de eletrofloculação \\ O sistema fotovoltaico utilizado} para alimentar a fonte de corrente contínua é apresentado na Figura 1a (Nascimento et al., 2015). Foi construído para servir como uma central de recargas para celulares, tablets, notebooks, além de servir como local de integração para os estudantes e servidores do Instituto Federal de Educação, Ciência e Tecnologia da Bahia (IFBA), Campus Paulo Afonso. Sua construção básica conta com a seguinte estrutura: a) Inversor de frequência: Inversor de Onda Modificada Hayonik, $400 \mathrm{~W} 12 \mathrm{~V} / 127 \mathrm{~V}$; b) Controlador de Carga CMTP02 $12 \mathrm{~V}$ e 10 A; c) Placa Solar: Golden Genesis PV110E, $110 \mathrm{Wp}$; d) Bateria: Tudor estacionária $45 \mathrm{Ah}$. O tratamento da água de lavagem nesse processo foi realizado em reator eletroquímico operado em batelada (béquer de vidro, volume útil 0,5 L) constituído de dois eletrodos de alumínio construídos a partir da reutilização de latinhas recicláveis de refrigerante com $9 \mathrm{~cm}$ de comprimento e $3 \mathrm{~cm}$ de largura. Os eletrodos foram fixados no reator, nos quais foram fixados fios de cobre ligados à fonte de corrente contínua (1,0 A) alimentada por um sistema fotovoltaico, conforme o esquema apresentado na Figura 1b. Foi adicionada ao reator $0,2 \mathrm{~L}$ da solução a ser tratada, previamente caracterizada quanto às variáveis investigadas $(\mathrm{pH}$, turbidez, DBO5, DQO, cor aparente, óleos e graxas) proveniente da água de lavagem obtida na produção do biodiesel. Na sequência, o sistema foi operado durante $10 \mathrm{~min}$ e posteriormente filtrado e as variáveis físicas e químicas reavaliadas. 


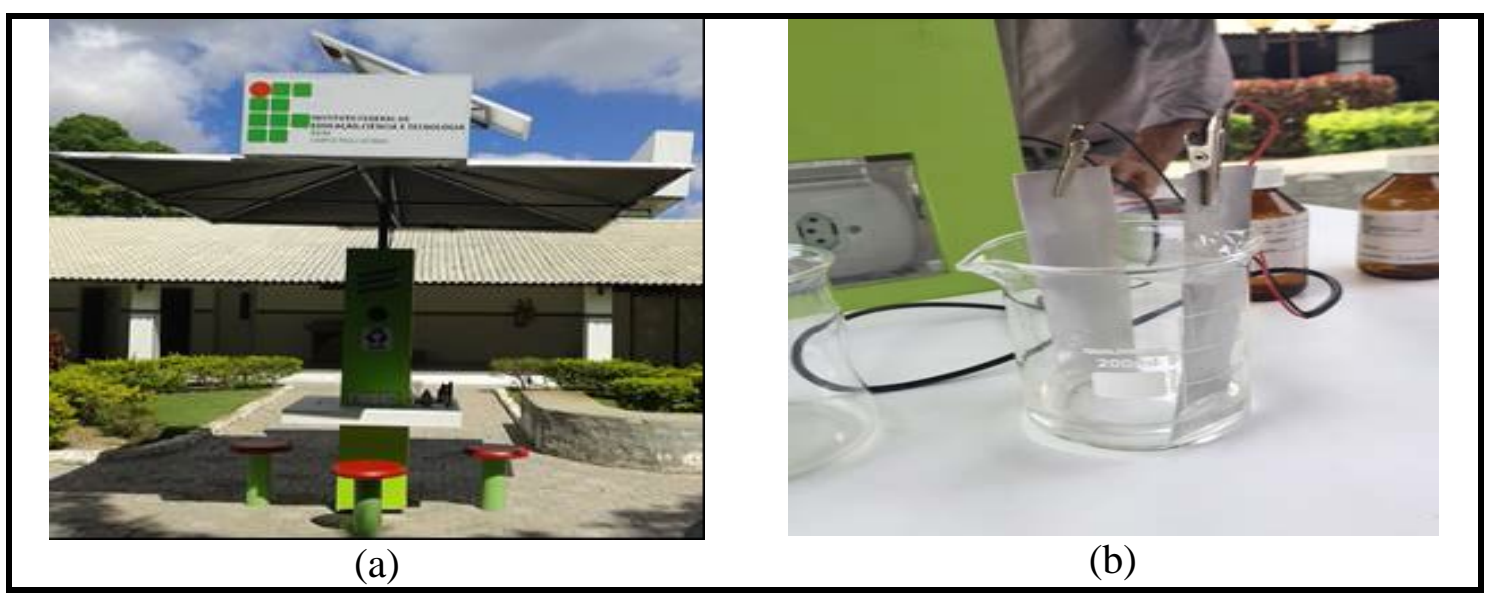

Figura 1. a) Protótipo sistema fotovoltaico; b) Montagem do reator eletroquímico para eletrofloculação da água de lavagem do biodiesel.

\subsection{Determinação do $\mathbf{p H}$}

Os valores de $\mathrm{pH}$ das soluções brutas e pós-tratamento das águas de lavagem do biodiesel foram medidos via pHmetro digital (Quimis, modelo: Q400AS) a $25^{\circ} \mathrm{C}$.

\subsection{Determinação da turbidez}

As medidas de turbidez foram realizadas via método nefelométrico (Eaton et al., 2005), em turbidímetro de bancada (Turbidímetro multiprocessado DLM 2000B, Del Lab®).

\section{DQO}

\subsection{Determinação de DBO5 e}

As análises de DQO foram realizadas via método colorimétrico (Standard Methods $5220 \mathrm{D}$ ) com bloco digestor do tipo TE-021 DryBlock Digestor (TECNAL). A DQO nas amostras foi quantificada por espectrofotometria (Spectrophotometer SP1105, Bel Photonics), tomando-se como branco um padrão água destilada (BioClass) (Eaton et al., 2005).

As análises de DBO5 recorreram ao método definido no Standard Methods 5210 B (Eaton et al., 2005), com determinação quantitativa posterior das amostras em um oxímetro (Digimed, modelo DM-4D).

\subsection{Determinação da cor aparente}

As medidas de cor aparente das águas de lavagem foram realizadas por leituras de absorbância, medidas em espectrofotômetro de UV (Spectrophotometer SP2000UV, Bel Photonics), calibrado com filtro de $460 \mathrm{~nm}$ (Eaton et al., 2005).

2.7. Determinação de óleos e
graxas
Para a determinação do teor de
óleos e graxas utilizou-se o método
gravimétrico por meio de extração líquido-
líquido. As amostras foram acidificadas
com ácido sulfúrico, a fim preservá-las,
bem como favorecer a hidrólise ácida no
meio. Em um funil de separação, contendo
a amostra acidificada, foram colocados
100 mL de éter de petróleo, seguindo uma
agitação por 5 min. Após a separação das
fases, o solvente foi levado para uma coluna
de carbonato de cálcio, a fim de retirar todo
resíduo aquoso. Em seguida, o solvente foi
transferido para uma capsula de porcelana
previamente preparada a peso constante e
levado a uma estufa de secagem e
esterilização da Fanem, modelo $320-S E$ a
$70{ }^{\circ} \mathrm{C}$, para evaporação de todo o solvente
até permanecer a fase oleosa. Em seguida a
cápsula de porcelana foi levada ao

\section{graxas}

óleos e graxas utilizou-se o método gravimétrico por meio de extração líquidolíquido. As amostras foram acidificadas com ácido sulfúrico, a fim preservá-las, bem como favorecer a hidrólise ácida no meio. Em um funil de separação, contendo a amostra acidificada, foram colocados $100 \mathrm{~mL}$ de eter de petróleo, seguindo uma agitação por 5 min. Após a separação das rento resíduo aquoso. Em seguida, o solvente foi transferido para uma capsula de porcelana previamente preparada a peso constante e levado a uma estufa de secagem e esterilização da Fanem, modelo 320-SE a $70{ }^{\circ} \mathrm{C}$, para evaporação de todo o solvente cápsula de porcelana foi levada ao 
dessecador por $30 \mathrm{~min}$ e após o resfriamento foram pesadas. A massa de óleos e graxas foi calculada por diferença de pesagem das cápsulas antes e após o procedimento de extração (Cordeiro et al., 2015).

\section{Resultados e discussão}

Na Tabela 1 são apresentados os resultados das variáveis de caracterização das águas $(\mathrm{pH}$, turbidez, DBO5, DQO, cor aparente, óleos e graxas) correspondente à lavagem ácida e à lavagem com água destilada do processo de purificação do biodiesel e após o tratamento por meio da eletrofloculação.

Observando os resultados obtidos (Tabela 1), constatou-se que os valores de todas as variáveis avaliadas para a água oriunda da lavagem ácida, na purificação do biodiesel produzido, estão situados fora das especificações exigidas pela legislação. De modo similar, a água residual referente ao efluente de primeira lavagem, onde a única variável que obedece às especificações é o $\mathrm{pH}$. Destaca-se também o teor de óleos e graxas, que diminuiu na sequência da lavagem ácida durante a primeira lavagem, contudo apresentou ainda valor elevado, fora do exigido para descarte em corpos hídricos. A cor aparente da água após lavagem, em comparação com o padrão de água destilada, encontrou-se dentro das especificações exigidas pela legislação para descarte (Resolução CONAMA $n^{\circ}$ 430/2011), bem como a DQO e a DBO5.

Tabela 1. Características físicas e químicas dos efluentes bruto e tratado via eletrofloculação.

\begin{tabular}{|c|c|c|c|c|c|c|}
\hline Água & pH & $\begin{array}{l}\text { Turbidez } \\
\text { (NTU) }\end{array}$ & $\begin{array}{l}\text { Cor aparente } \\
\text { (UC) }\end{array}$ & $\begin{array}{c}\text { DQO } \\
(\mathrm{mg} / \mathrm{L})\end{array}$ & $\begin{array}{l}\text { DBO5 } \\
\text { (mg/L) }\end{array}$ & $\begin{array}{l}\text { Óleos e } \\
\text { Graxas }\end{array}$ \\
\hline Destilada & 6,00 & 0,80 & - & - & - & - \\
\hline $\begin{array}{l}\text { Lavagem ácida } \\
\text { (Efluente bruto) }\end{array}$ & 3,40 & 70,10 & 0,306 & $43.900,23$ & $39.600,14$ & 287 \\
\hline $\begin{array}{l}\text { Primeira lavagem } \\
\text { (efluente bruto) }\end{array}$ & 5,20 & 18,40 & 0,079 & $1.844,73$ & $1.256,98$ & 112 \\
\hline $\begin{array}{l}\text { Eletrofloculação } \\
\text { (pós-lavagem ácida) }\end{array}$ & 6,44 & 0,79 & 0,004 & $5.660,32$ & $2.376,44$ & 39 \\
\hline $\begin{array}{l}\text { Eletrofloculação } \\
\text { (pós-primeira } \\
\text { lavagem) }\end{array}$ & 6,56 & 0,55 & 0,003 & 332,05 & 242,60 & 21 \\
\hline $\begin{array}{l}\text { Resolução } \\
\text { CONAMA } \\
\text { 430/2011 }\end{array}$ & $\begin{array}{c}5,00 \mathrm{a} \\
9,00\end{array}$ & Até 40,00 & $\begin{array}{l}\text { Nível natural } \\
\text { do corpo } \\
\text { receptor }\end{array}$ & - & $\begin{array}{l}\text { Remoção } \\
\text { mínima de } \\
60 \%\end{array}$ & 50 \\
\hline
\end{tabular}

Na sequência à aplicação da eletrofloculação no tratamento do efluente gerado após a lavagem ácida, pode ser observado a atenuação do teor de óleos e graxas, enquadrando $o$ efluente nas especificações necessárias para descarte, conforme determinado na Resolução CONAMA n ${ }^{\circ}$ 430/2011. Na aplicação da eletrofloculação, após primeira lavagem do biodiesel, nota-se que os valores enquadram-se nas condições estabelecidas pela legislação de descarte. $\mathrm{O}$ pH da água de lavagem situou-se próximo da neutralidade, conforme as especificações indicadas, bem como foi possível verificar uma redução significativa na turbidez (97\%), DQO (85\%) DBO5 (87\%), óleos e graxas (84\%). Na Figura 2, pode ser observada de forma comparativa as águas de lavagem antes de depois do tratamento via eletrofloculação.

Segundo Brito et al. (2012), as águas residuais após o tratamento via eletrofloculação podem ser reinseridas na cadeia produtiva do biodiesel, servindo novamente como águas de lavagem. Tal alternativa é inviável, uma vez que no efluente tratado ainda há um teor de ferro ou alumínio (a depender do eletrodo utilizado) residual alto. A presença de tais metais acelera as reações de autoxidação do biodiesel (Knohte et al., 2006; Junqueira et al., 2015). 


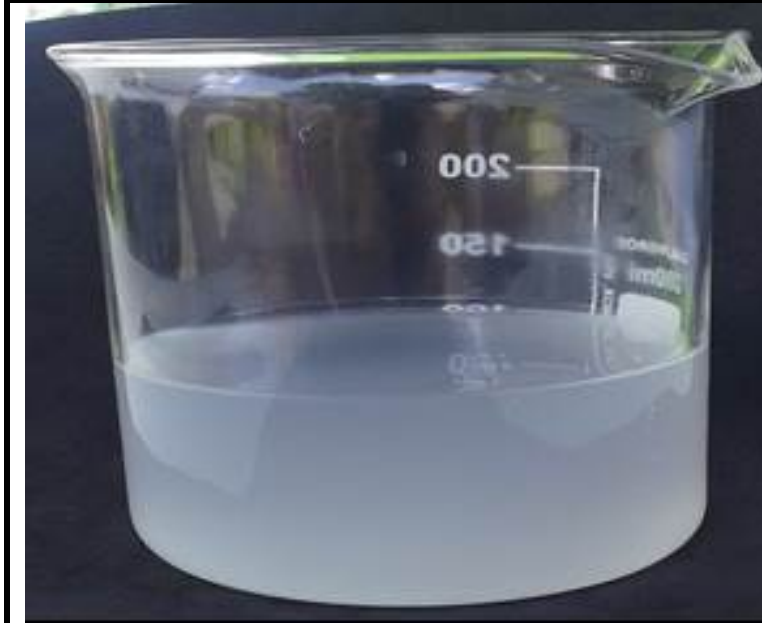

(a)

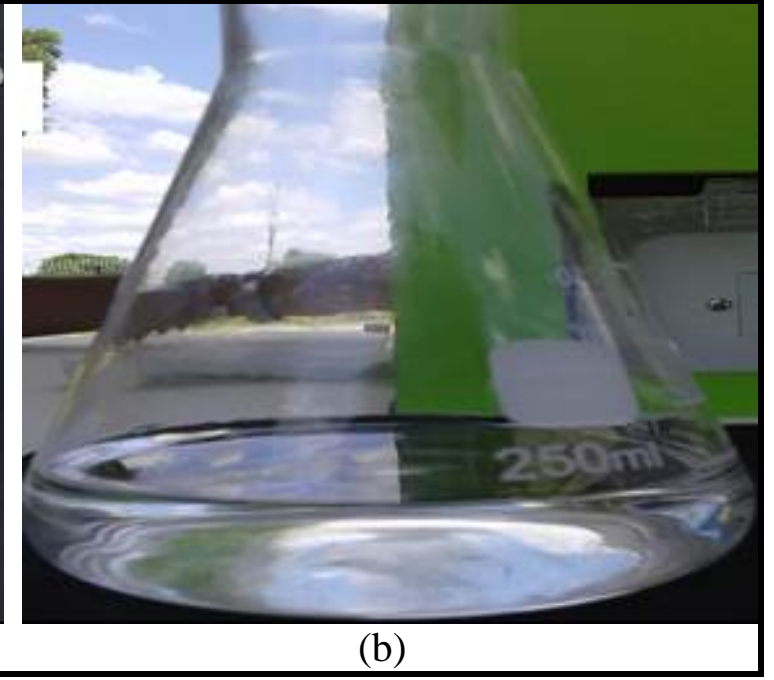

(b)

Figura 2. Águas de lavagem ácida antes e depois do tratamento via eletrofloculação.

No caso específico do presente trabalho o biodiesel foi produzido com $\mathrm{KOH}$ e tratado com eletrodos de alumínio. No processo de eletrofloculação, há a formação de hidróxido de alumínio e um residual de $\mathrm{KCl}$, tais compostos servirão de base para produção do alúmen de potássio que seria uma possibilidade de aplicação do efluente em questão.

Os pontos diferenciais no tratamento via eletrofloculação no presente trabalho é o uso de um sistema fotovoltaico que fornece energia para uma fonte de corrente contínua, e o uso do alumínio oriundos de latinhas recicláveis para a construção dos eletrodos usados no processo, tornando o tratamento atrativo, visto que é usado uma fonte de energia alternativa que propõe a diminuição de custos no processo, e também pelo fato de estar contribuindo com meio ambiente ao diminuir a quantidade de resíduos sólidos a partir da reutilização das latinhas de alumínio.

\section{Conclusão}

A utilização do sistema fotovoltaico como fonte geradora de energia para a aplicação da eletrofloculação, mostrou-se eficiente para o tratamento das águas excedentes da produção de biodiesel, visto que torna o processo mais econômico além de ser uma fonte alternativa de energia que causa menos impactos ambientais, assim como o uso de latinhas de alumínio como eletrodos que possibilita a reutilização das latinhas, minimizando o descarte inadequado de resíduos sólidos no meio ambiente.

Diante da concretização com sucesso do experimento, configura-se que o processo pode ser amplificado podendo ser feito um scale up. Demostrando que a utilização de uma fonte alternativa de energia e a reutilização pode ser aplicada para redução dos custos no processo de tratamento, sem comprometer a sua eficiência.

\section{Referências}

Brasil. Leis, Decretos, etc. Resolução CONAMA no 430, de 13 de maio de 2011. Dispõe sobre as condições e padrões de lançamento de efluentes, complementa e altera a Resolução n ${ }^{\circ}$ 357, de 17 de março de 2005, do Conselho Nacional do Meio AmbienteCONAMA. Disponível em: $<$ http://www.mma.gov.br/port/conama/legiabre. cfm?codlegi=646>. Acesso em: 15 set. 2015.

Brito, F. J.; Ferreira, O. V. L.; Silva, J. P. Tratamento de água de purificação do biodiesel utilizando eletrofloculação. Quimica Nova, v. 35, n. 4. p. 728-732, 2012.

Cavalcanti, L. A. P. Reologia e melhoramento das propriedades de escoamento a frio de biodiesel e suas misturas BX. Recife: Universidade Federal de Pernambuco, Departamento de Engenharia Química, 2013. (Tese de Doutorado). Disponível em: $<$ http://repositorio.ufpe.br/bitstream/handle/ 123456789/10548/TESE Luiz Antonio Pimentel Cavalcanti.pdf>. Acesso em: 15 set. 2015. 
Cordeiro, R. B.; Alexandre, J. I. S.; Silva, J. P. F.; Sales, D. C. S.; Cavalcanti, L. A. P. Purificação e reutilização de águas residuárias da produção de biodiesel por meio da eletrofloculação. Revista Brasileira de Gestão Ambiental e Sustentabilidade, v. 2, n. 2, p. 5158, 2015. Disponível em: <http://revista.ecogestaobrasil.net/v2n2/v02n02 a05.html>. Acesso em: 25 ago. 2015.

Eaton, A. D.; Clesceri, L. S.; Rice, E. W.; Greenberg, A. E.; Franson, M. A. H. (Eds.). Standard methods for the examination of water and wastewater. 21. ed. Washington, DC: American Public Health Association, 2005.

Ebiotecnologia. Possível uso de águas residuais para produção de biodiesel. Disponível em: $<$ http://www.ebiotecnologia.org/2012/04/possiv el-uso-de-aguas-residuais-para.html>. Acesso em: 20 set. 2015.

Fleck, L. Aplicação do controle estatístico de processos ao tratamento de um efluente têxtil por eletrofloculação. Medianeira: Universidade Tecnológica Federal do Paraná, Curitiba, 2011. (Trabalho de Conclusão de Curso).

Junqueira, C. N.; Franco, M. M.; Ruggiero, R.; Borges Neto, W.; Bueno, J. A.; Santos, D. Q. Contaminantes metálicos no biodiesel de soja. Anais do $10^{\circ}$ Congresso Internacional de Bioenergia, São Paulo, 2015.
Knothe, G.; Gerpen, J. V.; Krani, J.; Ramos, L. P. Manual do biodiesel. São Paulo: Edgard Blücher, 2006.

Nascimento, F. A.; Vieira, S. A.; Andrade Júnior, S. J.; Cavalcanti, L. A. P. Integração de um sistema fotovoltaico isolado e de coleta seletiva de resíduos em um quiosque multifuncional. Revista Brasileira de Gestão Ambiental e Sustentabilidade, v. 2, n. 2, p. 4350, 2015. Disponível em: <http://revista.ecogestaobrasil.net/v2n2/v02n02 a04.html>. Acesso em: 09 set. 2015.

Schllemer, M. A.; Santos, M. D.; Carletto, C. L.; Kalinke, C.; Rodrigues, M. B. Análise físico-química da água residuária proveniente do processamento de biodiesel. Synergismus Scyentifica UTFPR, Pato Branco, v. 3, n. 4, 3 p., 2008. Disponível em: $<$ http://revistas.utfpr.edu.br/pb/index.php/SysSc y/article/download/283/89>. Acesso em: 16 jun. 2013.

Singh, G. Electroflocculation on textile dye wastewater. Patiala: Thapar University, 2012. (Dissertação de Mestrado em Tecnologia em Ciência Ambiental). Disponível em: $<$ http://dspace.thapar.edu:8080/dspace/bitstream /10266/1943/1/electroflocculation.pdf >. Acesso em: 20 set. 2015 . 